\title{
Engineering Exploration Module for Rising 7th and 9th Grade Girls
}

\author{
Frances Van Sloun favansloun@gmail.com \\ Yaia Yang yang0091@stthomas.edu \\ Deborah Besser, PE, PhD deb.besser@stthomas.edu \\ University of St Thomas
}

\begin{abstract}
Two very different influences, science education and popular electronic device entertainment, both point to the need for engaging students with engaging, exciting, entertaining hands-on activities. Today's learning style coupled with a low percentage of engineering degrees awarded to women at $18.4 \%{ }^{1}$, influenced one summer programs attempt to engage young women in engineering. This paper outlines a module used to engage rising 7th and 9th grade girls in their exploration of engineering as a career. In this interactive module, girls learn about female engineering case studies/role models, historic female engineers, engineering practices, engineering careers, types of engineering and what engineering students do, through engaging activities. The goal of the module is to engage the imagination of young women as they visualize themselves in possible engineering careers.
\end{abstract}

\section{Background and Need}

University of St. Thomas STEPS (Science, Technology \& Engineering Preview) Summer Program originally adopted from the UW-Stout STEPs program, annually provides 280 rising 7th and 9th grade under-represented women a free on-campus residential engineering program. Close to 4000 participants have benefited from this free program which is now in its 15th year. An internal longitudinal study of the program showed that student interest in science had increased however there was no marked increase in engineering careers. Clearly a radical change was necessary. The curriculum was updated for the first time this year and Maker curricula, with a highlight on e-textile materials, were constructed by engineering students for the STEPS program. Additionally for the first time female engineering role models were engaged in and leading the primary STEPS curriculum content.

Critical for success of the STEPS program was an authentic exploration of engineering careers. Past participants pointed to the need for this information. As a school of engineering with the mission of providing service, and in turn opportunities, to the local and global community there arose a consensus that a critical component of the STEPS is sharing engineering career opportunities with participants. Given the limited number of access points which engineering careers has, it is critical that pathways be clearly articulated to participants in this early exploration program. 


\section{Exploration Module Components}

STEPS participants were provided with formal and informal opportunities to learn about engineering careers. Formal program units included segments called "Who's an Engineer", “Engineering Exploration Panels”, “Target Corporation: Design a Cooler”, ”Andersen Corporation: Bird Feeders” and “Engineering Student Led Career Exploration”. Informal program units allowed participants to learn more about specific areas of interest on their own time and in their own space.

\section{Who's an Engineer}

The Who's an Engineering component was provided as one of the opening activities as a means of introducing engineering careers, building participant efficacy and as a means of building 21st century learning skills of communication, collaboration, critical thinking and creativity. This module required girls to picture themselves and one another as future engineers as they traced one member of their group of ten. All members added essential components of what embodies an engineer. Final products included pictures of the globe, hearts, light bulbs going off in the engineer’s head, computers, cell phones, necklaces with "\$” signs, smiles with "positive attitude” written across, pencils, tool boxes, periodic tables, "thinking outside of the box", running shoes with "quick on feet” graphics. Recurring words included on these life size graphics included: creativity, happy, excited, anything is possible, education, patience, productive, ideas, inspiration, works well with others, responsibility, knows the engineering design process, engineers can do anything, determination, drive, smart, intelligent, hands on, math, problem solving skills, confident, open minded. This opening activity began the process of participants considering a personal identity around and self belief that engineering may be a career to consider.

\section{Engineering Exploration Panels}

Key to engineering exploration was modeling engineers who looked like the STEPs participants. Panels of female engineers shared their stories of how they choose engineering, what they did on a daily basis and why they would encourage young women to consider engineering today. Engineering professors, working engineers, recent engineering graduates and current engineering students all shared their narrative. Panel members were prepared with talking points from the National Academy of Engineering (NAE) “Changing the Conversation” initiative. The Changing the Conversation initiative has identified "effective engineering messages and taglines” including “engineers make a world of difference”, “engineers are creative problem-solvers”, "engineers help shape the future”, "engineering is essential to our health, happiness and safety", "turning ideas into reality" and "because dreams need doing”. 
The STEPS Director of Programming organized the collective Engineering Exploration Panel unit by having volunteer engineering professors take the lead in organizing the panels. This allowed for each of the five female faculty members to produce different products with the same end goal. Week one led by one of the most experienced engineering professors allowed for engaging high energy narratives to be shared. Key to this panel was 1. the compelling story of global engineering of the faculty members; 2 . an experienced working SWE engineer who is passionate about recruitment into engineering; and 3. a high energy young faculty member who is also passionate about engineering. Week two participants were significantly different. Panel members had entered into engineering through non-traditional paths. Week three was led by a engaging, young, high, energy level faculty member who invited an engineering friend. Week four and five were led by yet another engineering professor whose style was instructive. Week six and seven were led by an experienced, high energy, engineering professor who has extensive experience in engaging young students in informal educational settings.

\section{Target Corporation: Design a Cooler}

The STEPs program had two industry sponsored hands-on activities. Both industry sponsored activities were led by University of St. Thomas female engineers. The first program was sponsored and hosted by Target Corporation for the rising 9th grade STEPs program. In this one

hour session Janell Hibbard, a product engineer in Product Design and Development for Sporting Goods, interactively outlined her motivation for becoming an engineer, what engineering includes, the spectrum of engineering/technology job functions, engineering disciplines, product engineering, examples of 3D drawings/prototyping and packaging. The culminating activity included prototyping a cooler with product specifications. Key to the activity was discussion and redirection as the "designers" considered the key design criteria, product function, time/material constraints and communication.

\section{Andersen Corporation: Bird Feeders}

The second industry sponsored hands-on activity was the Andersen Bird Feeder construction project. Andersen provided two female engineers for all seven weeks 1 . to participate in the engineering panel 2. to lunch and talk informally with STEPS participants and 3. to lead the bird feeder construction project. The bird feeder construction project included a discussion on multiple engineering processes including manufacturing process, research process and design process. The STEPS participants had the benefit of learning from plant managers, design engineers, and corporate engineering managers. The bird house take away was one of the most beloved projects of the STEPS experience. 


\section{Engineering Student Led Career Exploration}

A student led career exploration activity enabled STEPS participants to look more in depth at specific careers. Groups of participants were given a packet of engineering careers from the site engineergirl.org and then instructed to seek out qualities in each career, which then was written on pieces of paper. Afterwards, each individual was asked to hand over those qualities to another participant who reflected those assets.

The purpose of this activity was to help stitch the Career Exploration Panel along with this activity to create a cohesive understanding of engineering careers, all while encouraging others to see themselves as engineers in an environment of young females closer to their age group. Most STEPS participants did not expect to share the qualities they found in certain careers to match those qualities to those members they knew. After a small exchange of those qualities, self-confidence skyrocketed. Many of them did not expect that they were viewed as smart or anticipate how they influenced people. With young camp counselor females and a student leading this activity as models STEPS participants were encouraged to seek the many engineering career options available.

\section{Informal Engineering Career Exploration}

STEPS participants were provided with an engineering design notebook as a learning tool. In addition to documenting the engineering design process that participants had through the program the engineering design notebook provided a means for engineering career reflection. A resource that was shared with participants included an engineering career resources page. Resources shared included 1. Engineering Girl (www.engineergirl.org), 2. Try engineering (www.tryengineering.org), 3. Exploring Career (http://www.bls.gov/k12/) 4. DOL Occupational Outlook Handbook (http://www.bls.gov/ooh/) and 5. Career Cornerstone Center (http://www.careercornerstone.org/). During pre-survey and post-survey completion times STEPs participants were encouraged to explore these sites. Additionally participants left the program with these resources to reference later.

\section{Assessment}

The STEPs program self monitors under a continuous improvement model. Data collected for this purpose includes participant pre and post, surveys, draw an engineer ${ }^{3}$ test, and analysis of engineering design notebooks. The draw an engineer (DAE) test is a tool used to measure students' understanding of engineering. Rigorous analysis by others has provided analytical and descriptive tool functions which has measured gender understanding, engineering function understanding and engineering tool measurements. DAE used in STEPS program as a measure for improvement and as a comprehensive analysis tool which allowed for trends to emerge including participants increased inclusion of women and smiles from pre to post analysis. 
Analysis of the participants notebooks indicated an increased interest in engineering careers. Participant comments included an interest in learning more "info about each branch of engineering”, "where engineers work" as well as an interest in learning more about "how to build things". Assimilation of possible engineering careers was reflected in participants comments that “designing isn’t hard”.

Pre and post surveys provided a sketch of the participants and their response to program components. Pre-surveys indicated that $65 \%$ of participants did not personally know an engineer. Post surveys of participants reflected the higher level of engagement and interested that the more active sections of the exploration model included. Additionally the high level of engagement shared by presenters was actively reflected by the participants in their rating of the components. That is, the more energized and positive the presenter was the more likely the audience was to rate the presenter higher.

\section{Findings and Next STEPS}

The explore engineering module was created as an introduction to engineering careers. High energy, engaging, hand-on modules were well received by participants. A rubric for assessment of 1 . career content, 2. engineering design process engagement and 3. presenter enthusiasm is currently under development. These elements will be further studied and included in future STEPS programming.

\section{Bibliography}

1. National Research Council. (2012) A Framework for K-12 Science Education: Practices, Crosscutting Concepts, and Core Ideas. The National Academies Press, Washington, DC.

2. Yoder, B. L. (2011) "Engineering by the Numbers" ASEE, Washington, DC.

3. Cunningham, C. \& Knight, M. (2005) 'Draw an Engineer Test: Development of a Tool to Investigate Students' Ideas about Engineers and Engineering” Proceedings of the ASEE Annual Conference, Portland, OR. 